\title{
Isolation and Identification of Physiologically Important Sterol glucoside from Basella rubra Linn
}

\author{
Singha Sumeru \\ Department of Chemistry, University of Science and Technology, Meghalaya, Khanapara, India. \\ DOI: 10.29322/IJSRP.12.01.2022.p12114 \\ http://dx.doi.org/10.29322/IJSRP.12.01.2022.p12114
}

\begin{abstract}
Steroids have very important physiological impact on biological system. B-sitosterol and stigmasterol glucosides isolated from natural sources enjoy immense importance in neat and substituted from. This paper reports for the first time the detection and successful isolation of these sterol members in good yield from the medicinally important plant basella rubra Linn.
\end{abstract}

Index Terms- Basella rubra, sterol, natural product.

\section{INTRODUCTION}

$\mathrm{P}$ lants, microorganisms, vertebrates and invertebrates are the fine biochemical factories for the biosynthesis of both primary and secondary metabolites. Their ingenuity in creating diverse structures with generous sprinkling of the functionalities is thrilling. This is the outcome of evolution through millions of years during which they have been withstanding many tough tests of survival (The Europress Millennium Encyclopaedia, 2000). The genus Basella (Chenopodiaceae) containing about nine species is distributed in India (widely in Assam, Meghalaya, Manipur, West Bengal and Maharashtra), tropical Africa and South-East Asia. Basella rubra Linn is a traditional Indian folklore medicine used to treat bleeding piles, pimples, boils, tumour, whooping cough, urticaria, to cure irritations and itching, to heal ringworm, eczema, septic wounds, ulcers, anaemia, as an effective tooth powder that cures many disease of gum and teeth, cure all evil effects of alcoholism, biliousness, leprosy, etc. (Ghose, 2000).

Basella rubra had also been used as natural dye. Mell (1937) had reported the isolation of a purple dye from the plant. Cao et al. (1991) have extracted a red pigment from the fruit of Basella rubra. It is a new pigment for food. The ability for colouring is good. It is bright purple at $\mathrm{pH}^{3-7}$. It is decomposed under the effect of light, heat and metal ions such as $\mathrm{Fe}^{2+}, \mathrm{Fe}^{3+}$ and $\mathrm{Cu}^{2+}$. The stability of the pigment to UV- rays could be improved on adding an appropriate amount of ascorbic acid into the solution of the colourant. It showed as identical peak to that of betanin on UV- Visible spectrum and IR spectrum of purified Basella red pigment also gave the characteristics absorption of betacyanins.

A red colouring material resistant to heat induced discolouration for food, feeds, pharmaceuticals, cosmetics, etc. using the fruit juice of Basella rubra has been isolated (Nishimato and Hirose, 1991).

Carotenoids were detected in leaves of Basella rubra and the corresponding vitamin A values were calculated. The major carotenoids detected in all the species were $\beta$-carotene, small amounts of $\alpha$-carotene and traces of other carotenoids (Penteado, 1987).

Glaessgen et al. (1993) have isolated Betacyanins from fruits of Basella rubra. They have reported the presence of betanidin monoglucoside as the major betacyanin and its 4coumaroyl and feruloyl derivatives as minor components by Ion spray mass spectrometry and tandem mass spectrometry of the fresh juice from the fruits of Basella rubra.

The seeds of Basella rubra contained oils (36.9\%), fatty acids (50.3\%), linoleic acid (49.1\%) and protein (23.1\%) (Killur et. al, 1983).

Although comparatively fewer reports are available about Basella rubra, yet the chemical and medicinal properties as investigated ont he various species of Basella genus and on the various species rubra, it is likely that Basella rubra Linn. Also may have such or related chemical constituents and properties.

\section{DESCRIPTION OF THE PLANT}

The plants Basella rubra Linn. and Basella alba Linn. belong to the family, Chenopodiaceae and sub-family, Basellaceae. The Basella rubra Linn(red variety) and Basella alba Linn. (white variety), local name pui are herbs with watery sap having very long, slender, twinning to the right, succulent, glabrous, much branched stem. Leaves are alternate, broadly ovate, acute or acuminate, thick, apiculate, entire, base often cordate, narrowed into the petiole, petioles $1.2-2.5 \mathrm{~cm}$ long.

For the present work, the leaves of both the white and red varity of plants were collected from several growing areas in Barak Valley during April to August, 2008. The plant materials were air dried at ambient temperature and then powdered. The powdered materials were used for the further experimentations.

\section{EXTRACTION}

The powdered leaves $(1.0 \mathrm{~kg})$ were extracted by treating with acetone for a week, the colour of the solution changed to deep green. The solution was filtered, distilled to give a deep green semi-solid mass which was subjected to TLC using petroleum ether-ethyl acetate (8:2), showed five spots. The deep green semisolid was subjected to silica gel column chromatography (100-200 mesh, 30g column, $16 \mathrm{~cm}$ length) employing petroleum etherethyl acetate $(8: 2)$ as elute. From the column, four compounds were isolated- a light green compound, a blackish solid, a yellowish solid and a light yellow compound. 


\section{RESULTS AND DISCUSSION}

The dried powdered leaves of Basella rubra Linn. were extracted independently with acetone after defating with hexane. The acetone extract, after removal of the solvent under reduced pressure, was separate and purified on silica gel column. Two compounds (compound1 and compound2) were isolated from the leaves of Basella rubra Limn.

On elution of the column of the acetone extract of the leaves of Basella rubra with pet. Eter-ethyl acetate (95:5\%), a semisolid grayish compound, which was recrystallized from methanol to give a colourless compound (compound1), was isolated and it was found to be $\beta$-sitosterol, was confirmed by comparing with the melting points and spectral data of the authentic sample.

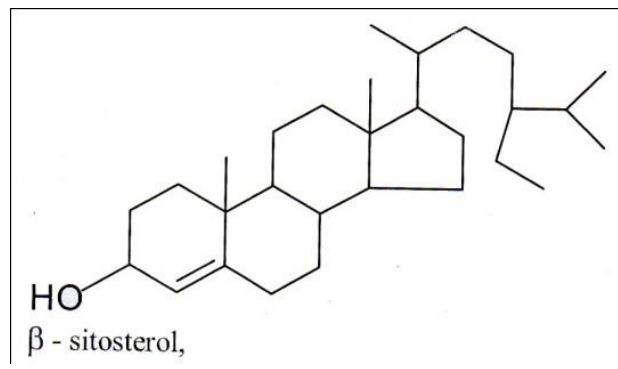

When the column was further eluted with pet. ether-ethyl acetate (87:13\%), a ligt yellow compound (compound2) was obtained, which was crystallized with methanol to give a colourless compound. The compound was found to be stigmasterol glucoside. The structure of stigmasterol glucoside, was determined by its IR, ${ }^{1} \mathrm{H}$ NMR, ${ }^{13} \mathrm{C}$ NMR spectral data.

Its IR showed peak at $3408 \mathrm{~cm}^{-1}$ due to hydroxyl group. Its ${ }^{1} \mathrm{H}$ NMR spectrum showed the peaks of methyl groups at $\delta 0.68$, $0.82,0.85,0.93,1.01$ due to H-18, H-27 \& 29, H-26, H-21, H-19 respectively. The olefinic protons at $\mathrm{H}-22 \& \mathrm{H}-23$ showed the peaks at $\delta 5.14 \& \mathrm{H}-23$ respectively. The protons corresponding to sugar moiety showed the peaks at $\delta 4.39,3.23,3.58$,

Isolation and identification of physiologically.

$3.35,3.76$ and 3.80 respectively. The ${ }^{13} \mathrm{C}$ NMR spectrum of showed at $\delta 10.8,18.2,17.7,18.0,10.9$ due t methyl groups at C-8, C-19, C-21, C-26, C-27 \& C-29 respectively. The olefinic carbon atoms at C-5, C-6, C-22 \& C-23 showed the peaks at $\delta$ $139.3,121.2,137.3 \& 128.9$ respectively. The mass spectrum showed at $\mathrm{m} / \mathrm{z} 397$ due to $[(\mathrm{M}+\mathrm{I})$ - Glucose $\}$. Thus, from all the above spectral data, the structure of compound is assigned as Stigmasterol glucoside.

\section{CONCLUSION}

Two important sterols $\beta$-sitosterol and Stigmasterol glucoside were identified and isolated in good yield from the leaves of wild plants, Basella rubra Linn

\section{REFERENCES}

[1] The Europress Millenium Encyclopedia, (2000). (CD ROM Cambridge University Pess.

[2] Ghos, G.K., (2000). Herbs of Manipur, H.P.H. Publishing Corporation: New Delh, 2, 1068-1069.

[3] Mell, C.D., (1937), A purple dye from the species of Baella, Chem, Abs, 31, 8256-8996

[4] Cao,Y., Hu,L., Tang, Z., Ye,Q., (1991) stability of natural Basella red pigment, Chem. Abs., 115, 62, 278382a.

[5] Nishimato, T., Hirose, R., (1991). Red- colouring method using Basella rubra fruit juice, Chem.Abs., 115,790,181899y.

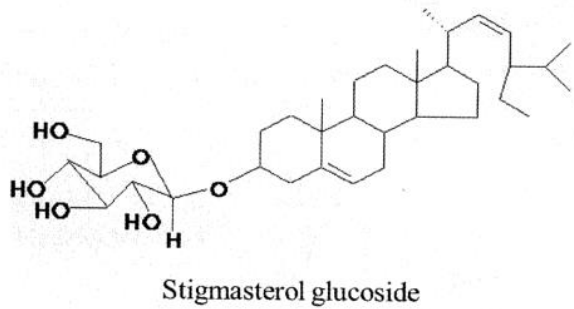

[6] Penteado, M.D.V.C., Minazzi, R.S., Regina, S., Bicuda, D.A.L., (1987). Carotinoids and provitamin A. activity of vegetable leaves consumed in northern Brazil, Chamical Abstract, 107,609,132949d.

[7] Glaessgen, W.E., Metzger, J.W., Heuer, S., Stract, D., (1993). Betacyanins from fruits of Basella rubra, Phytochemistry, 33(6) 1525-1527

[8] Killur, M.H., Mahajansheti, C.S., Kaimal, T.NB. and Lakshminarayana, G., (1983). Characteristics and composition of some minor seeds and the oils., J. Oil Tchnol. Assoc. India, 15(3), 43-45.

\section{AUTHORS}

First Author - Singha Sumeru, Department of Chemistry, University of Science and Technology, Meghalaya, Khanapara, India., Author: e mail: smrsingha67@gmail.com

Mobile No.: 09101400271 